\title{
Clinical, neuropathologic, and genetic studies of a large spinocerebellar ataxia type 1 (SCA1) kindred: $(\mathrm{CAG})_{\mathrm{n}}$ expansion and early premonitory signs and symptoms
}

\author{
D. Genis, MD; T. Matilla, PhD; V. Volpini, MD, PhD; J. Rosell, MD; A. Dávalos, MD, PhD; \\ I. Ferrer, MD, PhD; A. Molins, MD; and X. Estivill, MD, PhD
}

\begin{abstract}
Article abstract-We report the clinical, neuropathologic, and genetic studies of a large kindred (family M-ADCA1) with autosomal dominant spinocerebellar ataxia type 1 (SCA1), ascertained in 41 members, with clinical data available in twenty-two. The mean age of onset was $36.3 \pm 6.2$ years (ages, 26 to 52 ), the mean duration of the disease was $15.8 \pm 6.5$ years (range, 10 to 28 years), and the mean age at death was $54.1 \pm 9.5$ years (ages, 39 to 72 ). Premonitory signs and symptoms appeared earlier than the usual onset symptoms in many of the clinically unaffected patients who inherited the mutated SCA1 gene. Anticipation was present when we compared the seventh and eighth generations. A more severe course of the disease occurred in offspring of affected males. Neuropathologic examination, performed on three patients, showed the usual findings of SCA1; Golgi and immunocytochemistry studies suggested primary damage of the Purkinje cells. We analyzed the CAG-repeat mutation responsible for the SCA1 phenotype in a total of 41 family members. There was expansion in 19 subjects (10 clinically affected, seven with early signs and symptoms, and two asymptomatic individuals), and all showed heterozygosity, with one allele between 41 and 59 repeats (SCA1 mutation) and the other in the range of 6 to 39 repeats (normal range). The clinical analysis of "at risk" patients with the SCA1 mutation showed that minor signs and symptoms begin before full clinical diagnosis, and these premonitory manifestations can herald full development of SCA1 by years.
\end{abstract}

NEUROLOGY 1995;45:24-30

The autosomal dominant spinocerebellar ataxias (ADCAs) are a group of inherited disorders showing clinical, neuropathologic, and genetic heterogeneity. ${ }^{1,2}$ Besides cerebellar manifestations, dementia, pyramidal signs, and ocular motor and spinal cord dysfunction are also present.

In 1974, Yakura et $\mathrm{al}^{3}$ observed linkage between one form of dominant ataxia and the HLA locus. Later, Jackson et $\mathrm{al}^{4}$ confirmed that a form of spinocerebellar ataxia (SCA) showed linkage to chromosome 6. This locus was named SCA1, and this variant of dominant ataxia is known as SCA type 1 (SCA1). ${ }^{5}$ Other SCA1 kindreds showed linkage with this locus. ${ }^{6-10}$ The development of markers closely linked to SCA1 has allowed genetic studies in affected families. ${ }^{6,11-13}$ More recently, Orr et al ${ }^{14}$ isolated a $10-\mathrm{kb}$ transcript showing high expression in brain and skeletal muscle, containing an unstable trinucleotide (CAG) $)_{n}$ repeat, which is expanded in SCA1 patients. This $(\mathrm{CAG})_{n}$ repeat expansion is the mutation causing SCA1, and the mutated gene is now known as the SCA1 gene.

We describe here the clinical, neuropathologic, and genetic studies in a large family with dominant ataxia (family M-ADCA1) that segregates with the SCA1 locus and has the (CAG) $)_{n}$ mutation..$^{15}$ The molecular detection of clinically unaffected patients has allowed the identification of disease premonitory manifestations years before the appearance of the usual onset symptoms.

Methods. Genealogic and epidemiologic data. Genealogic data for family M-ADCA1 were obtained for 400 subjects with a common ancestor born in 1735 . Data

See also page 1

From the Neurologic Unit (Drs. Genis, Dávalos, and Molins), Hospital de Girona "Dr. Josep Trueta," Girona; and the Molecular Genetics Department (Drs. Matilla, Volpini, and Estivill), Cancer Research Institute (I.R.O.), Hospital Duran i Reynals, and the Neuropathologic Unit (Dr. Ferrer), Department of Pathology, Hospital "Princeps d'Espanya," Ciutat Universitària de Bellvitge, L'Hospitalet del Llobregat, and the Genetics Service (Drs. Rosell and Estivill), Hospital Clínic, Barcelona, Catalunya, Spain.

Received February 24, 1994. Accepted in final form August 15, 1994

Address correspondence and reprint requests to Dr. David Genis, Neurologic Unit, Hospital de Girona "Dr. Josep Trueta," 17007 Girona, Spain. 


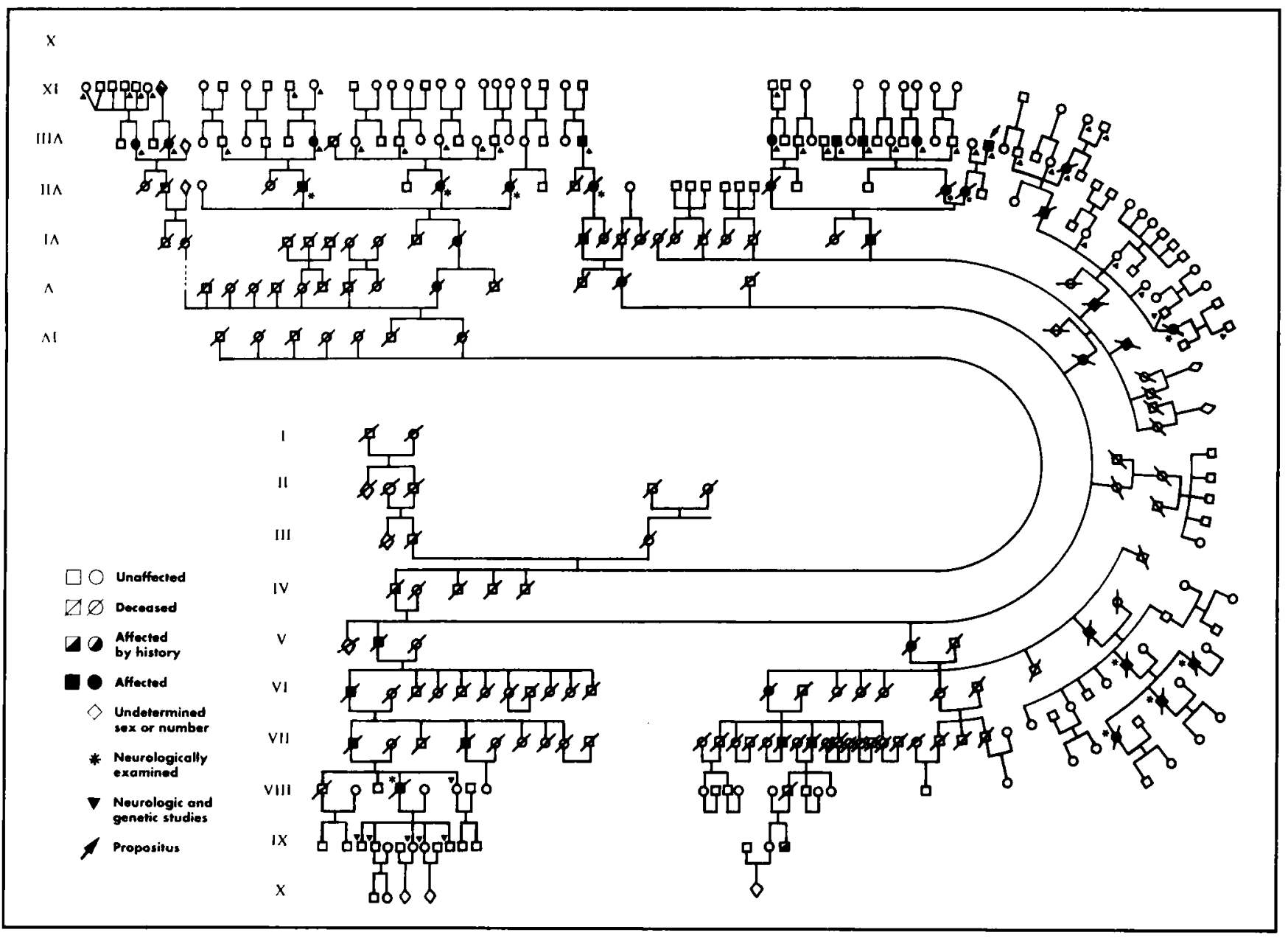

Figure 1. Pedigree of $M$ family.

around and before 1870 were obtained from church archives. The pedigree spans over 10 generations (figure 1). This family has lived for three centuries in the Girona area (Catalonia, Spain).

Clinical and neuropathologic data. Fourteen patients were examined by D.G., and clinical data from three hospitals were obtained for a further eight patients. Age of onset, duration of the disease, age at death, onset symptoms, and general clinical information were obtained from these clinical registers.

An "at risk" subject was defined as "the clinically unaffected offspring of an affected individual." Thirty-three asymptomatic at-risk subjects and their offspring (18 years or older) have been examined. Those at-risk subjects who had the mutation, as determined by molecular genetic studies, composed the "at risk/mutated" group, whereas those nonmutated individuals composed the "at risk/normal" group. All patients were neurologically examined at least once. A questionnaire for all the at-risk individuals was prepared in an effort to detect minimal or incipient symptoms of the disease. Responses were registered and even minor signs of SCA were included.

A neuropathologic study was carried out on three patients: VII-78, VIII-4, and VIII-43. The microscopic study was performed on formalin-fixed, dewaxed paraffin sections. A detailed description of the changes and a study using the Golgi method, and neurofilament and calcium binding protein immunocytochemistry, have been reported elsewhere. ${ }^{16}$

Genetic studies. Genetic studies were carried out on 65 subjects, 10 affected and 55 clinically unaffected individuals. DNA was obtained from blood lymphocytes for all patients except two, from whom samples of brain and liver postmortem tissues were used. Pairwise linkage analysis for the DNA markers analyzed was performed using the frequencies obtained in 200 unrelated individuals of the Spanish population or those published for each marker. ${ }^{6,12,17}$

Linkage analysis between SCA1 and D6S89 and between SCA1 and D6S109 was performed using the LINKAGE program, version 5.1, with the appropriate corrections for age-dependent penetrance, as reported previously. ${ }^{15,18}$ The CAG repeat at the SCA1 locus was analyzed using the primers and electrophoresis conditions described elsewhere. ${ }^{14,15}$

Results. Chronologic data. Ataxia was ascertained in 41 family members ( 20 men, 21 women), but clinical data were obtained for only 22 of them (nine men and 13 women). Eight patients belonged to the seventh generation and 14 to the eighth. Both sexes were equally at risk of developing the disease. The disease in this family is inherited as an autosomal dominant trait with complete penetrance by the age of fifty-two. In 13 subjects, the affected parent was the father and in nine, the mother. There were 43 known at-risk subjects (23 men and 20 women); of these, 33 were clinically 


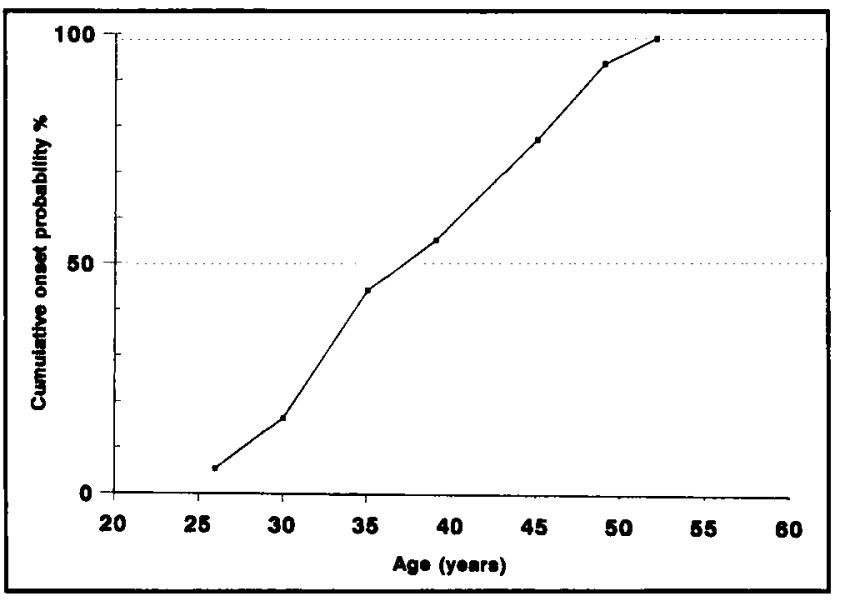

Figure 2. Cumulative onset probability curve of $M$ family.

studied and genetically analyzed (figure 1).

The mean age of onset was $36.3 \pm 6.2$ years. A cumulative penetrance curve was constructed from affected individuals by the method of Ott ${ }^{19}$ (figure 2 ). The mean duration of the disease was $15.8 \pm 6.5$ years. The mean age at death was $54.1 \pm 9.5$ years. There were no sex-related differences in these data, but younger onset (anticipation) and shorter duration of the disease, with earlier death, were observed in the eighth generation compared with the seventh. Differences in the mean duration of the disease and the mean age at death (table 1) suggested a trend toward a shorter course of disease and an earlier age at death for offspring of an affected father compared with offspring of an affected mother.

Onset symptoms in SCA1 patients. Ataxia was the initial reported symptom in 17 patients. In 14 of these patients, ataxia was the only symptom at presentation; in two patients, ataxia was accompanied with dysarthria, and in one, with fatigue. In another patient, the disease began with fatigue 1 year before the development of ataxia and dysarthria; in two others, dysarthria was the first sign of disease; and in the remaining two patients, the initial symptom was unknown.

Clinical findings in SCA1 patients. A complete cerebellar syndrome developed in all patients during the course of the disease, with ataxia, dysarthria, titubation, dysdiadochokinesia, and dysmetria. Pyramidal signs were detected in 10 of 22 , dementia in eight, and ocular motor disorders in nine.

Cognitive dysfunction was present in two clinical forms. In some cases, a frontal-like syndrome presented with euphoria and emotional lability, but in most patients, a change in the usual behavior appeared only in the last years of the disease, with nocturnal shouting and crying, irritability, and aggressiveness. A neuropsychological study was impossible in these patients.

Ocular motor findings in some of our patients included an absence of optokinetic nystagmus, upward gaze palsy, and lid retraction. Dysphagia
Table 1. Chronologic data*

\begin{tabular}{|c|c|c|c|}
\hline & $\begin{array}{l}\text { Mean age } \\
\text { at onset }\end{array}$ & $\begin{array}{c}\text { Mean } \\
\text { duration }\end{array}$ & $\begin{array}{c}\text { Mean age } \\
\text { at death }\end{array}$ \\
\hline $\begin{array}{l}\text { Total } \\
\mathrm{N} \\
\text { Range }\end{array}$ & $\begin{array}{c}36.3 \pm 6.2 \\
22 \\
(26-52)\end{array}$ & $\begin{array}{c}15.8 \pm 6.5 \\
14 \\
(10-28)\end{array}$ & $\begin{array}{c}54.1 \pm 9.5 \\
14 \\
(39-72)\end{array}$ \\
\hline $\begin{array}{l}\text { Seventh } \\
\text { generation }\end{array}$ & $40.3 \pm 7.6$ & $20.8 \pm 5.1$ & $62.3 \pm 6.3$ \\
\hline $\mathrm{N}$ & 8 & 8 & 8 \\
\hline $\begin{array}{l}\text { Eighth } \\
\text { generation }\end{array}$ & $33.4 \pm 8.6$ & $15.4 \pm 7.5$ & $45.3 \pm 6.8$ \\
\hline $\mathrm{N}$ & 14 & 6 & 6 \\
\hline$p<$ & 0.004 & 0.005 & 0.001 \\
\hline $\begin{array}{l}\text { Mother } \\
\text { affected (n) }\end{array}$ & $\begin{array}{c}38.9 \pm 8.5 \\
(9)\end{array}$ & $\begin{array}{l}25.2 \pm 4.2 \\
\quad(3)\end{array}$ & $\begin{array}{c}65.1 \pm 3.8 \\
\text { (3) }\end{array}$ \\
\hline $\begin{array}{l}\text { Father } \\
\quad \text { affected (n) }\end{array}$ & $\begin{array}{l}36.1 \pm 7.9 \\
\quad(13)\end{array}$ & $\begin{array}{l}15.6 \pm 4.5 \\
\quad(11)\end{array}$ & $\begin{array}{l}51.2 \pm 8.9 \\
\quad(11)\end{array}$ \\
\hline $\mathbf{N}$ & 22 & 14 & 14 \\
\hline$p<$ & 0.29 & 0.023 & 0.024 \\
\hline
\end{tabular}

with choking was a minor but constant finding in the M-ADCA1 family. When questioned, all patients had had dysphagia since the onset of disease although without serious problems until the last years of the clinical course.

Nine patients had weight loss and wasting that was not related to dysphagia. It started during the midcourse of the disease and was not modified by diet or drug therapy. Amyotrophy was also a very frequent finding, paralleling cachexia. A progressive restrictive respiratory failure with impaired cough mechanisms was observed in five patients, but this number is probably an underestimation because some patients have not been properly investigated. Respiratory failure was probably related to the anterior horn disease and amyotrophy. Chorea, torticollis, tongue atrophy, fasciculations, sphincter dysfunction, and deep sensation loss were less frequent findings.

Fourteen of the patients are dead. In 11, death was caused by pneumonia, probably combined with restrictive respiratory failure; one patient died of a pneumothorax, and another patient from sepsis. The cause of death was unknown for the remaining patient.

Neuropathologic studies. The most remarkable gross features were atrophy of the ventral part of the pons and middle cerebellar peduncles, with variable shrinkage of the cerebellum and inferior olives.

In the microscopic study, the cerebellar cortex showed loss of Purkinje cells and variable loss of granule cells. Neuron loss and gliosis occurred in the dentate nuclei. The inferior olives exhibited reduced numbers of neurons and increased numbers of astrocytes. Similar findings were present in the pontine nuclei. Involvement of the reticular forma- 


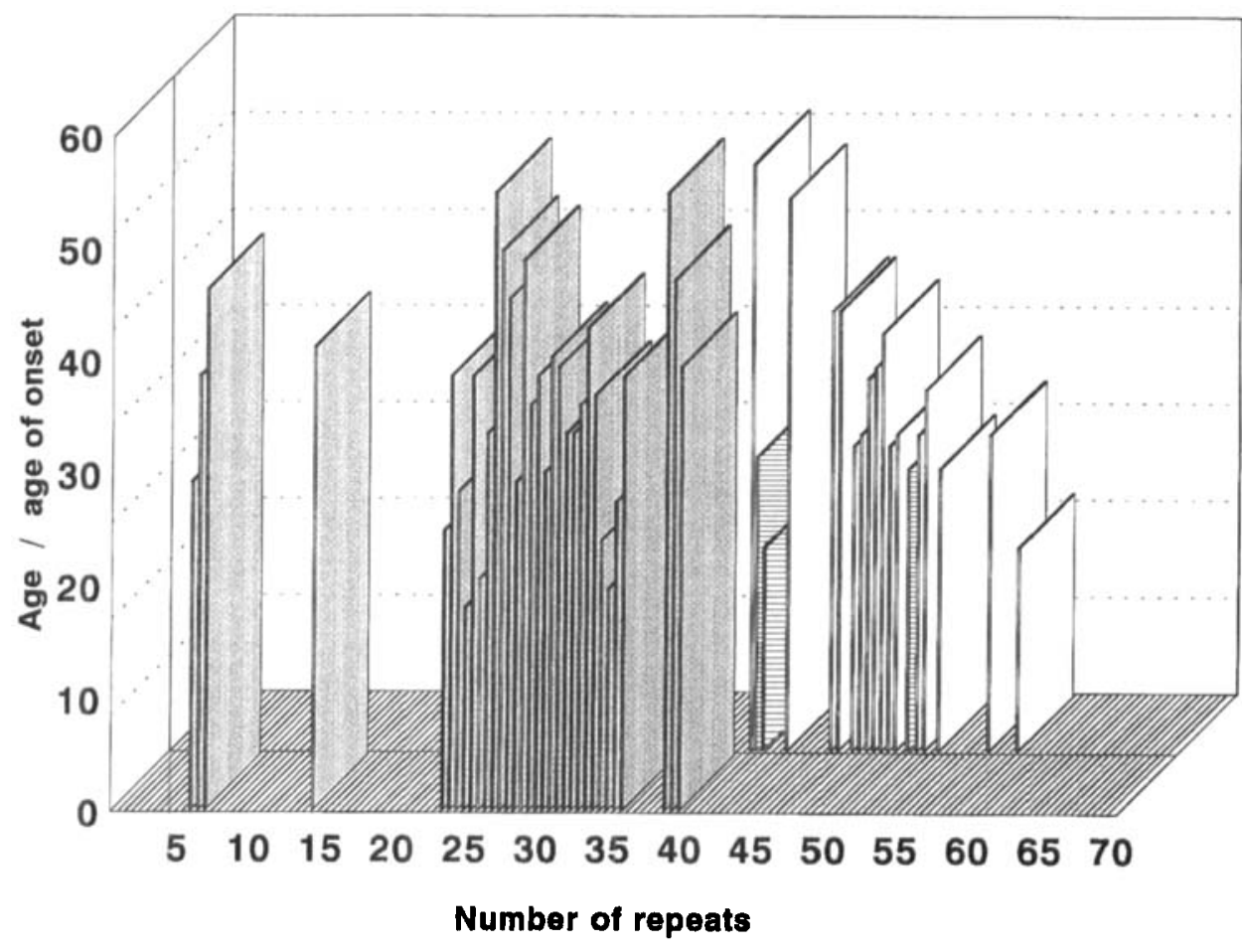

Figure 3. $(C A G)_{n}$ repeats in $M$ family. The at-risk unaffected group is at left (shaded). The affected group is at right (in white), with the three asymptomatic subjects (inserted horizontal bars). Age is the current age for the at-risk unaffected; age of onset is the age of the first detected symptom and sign for the affected group.

tion, nucleus ambiguus, dorsal nucleus of the vagus nerve, and hypoglossal nucleus was variable from one patient to another. Loss of neurons, pigment deposition in the neuropil, and gliosis were found in the substantia nigra. The striatum and more specifically the putamen, pallidum, and subthalamic nucleus were also variably affected. The cerebral cortex was normal in every patient.

Golgi and calbindin immunocytochemistry studies showed loss of dendrites, reduced dendritic arbors, decreased formation of proximal spines, abnormal accumulation of neurofilaments, and early formation of axonal spheroids. These findings suggest primary damage of Purkinje cells in SCA1.16

$S C A 1(C A G)_{n}$ expansion analysis. Linkage studies showed that the disease was in complete linkage disequilibrium with D6S89. ${ }^{15}$ Analysis of the CAG-repeat mutation, responsible for the SCA1 phenotype, showed that 10 clinically affected and nine at-risk individuals were heterozygous, with the disease allele between 41 and 59 repeats. Analysis of 60 normal individuals showed a total of 13 different alleles ranging between six and 39 repeats. The difference in repeat size between affected and unaffected individuals was very narrow in the M-ADCA1 family, with a 39-repeat allele associated with a normal phenotype and a 41-repeat allele associated with SCA1. ${ }^{15}$ There was an inverse correlation between the number of CAG repeats and the age of onset of the disease (figure 3).

The mean number of repeats in affected individuals of the eighth generation was $47.7 \pm 4.5$ and of the ninth generation, $53.5 \pm 3.8(p<0.05)$ (table 2$)$. Considering sex, in affected men the mean number
Table 2. Mean CAG repeats in relation to sex, generation, and parental sex

\begin{tabular}{|lcl|}
\hline & $\begin{array}{c}\text { Mean } \\
\text { repeats } \pm \text { SD }\end{array}$ & \\
& & \\
Men $(\mathrm{n}=8)$ & $48.0 \pm 3.77$ & NS \\
Women $(\mathrm{n}=11)$ & $49.8 \pm 5.47$ & \\
Eighth generation $(\mathrm{n}=13)$ & $47.7 \pm 4.53$ & p<0.05 \\
Ninth generation $(\mathrm{n}=6)$ & $53.5 \pm 3.87$ & \\
Father affected $(\mathrm{n}=5)$ & $50.2 \pm 3.43$ & NS \\
Mother affected $(\mathrm{n}=14)$ & $49.2 \pm 5.85$ & \\
\hline
\end{tabular}

of repeats was $48.0 \pm 3.77$ and in affected women, $49.8 \pm 5.47$. We observed that when affected fathers passed on the mutated SCA1 gene, the increase in the number of CAG repeats found in their offspring was larger $(50.2 \pm 3.43)$ than that seen when it was passed on by affected mothers (49.2 \pm 5.85). However, this difference is not statistically significant. We also observed that none of five sons of an affected father presented the CAG-repeat allele in the affected range ( $p=0.031$ ); in this line, the disease was transmitted through four generations only by males. In another line in which the disease was transmitted only by women through four generations, only one of six sibs had a $47 \mathrm{CAG}$ repeat disease allele.

Six parent-child transmissions of the CAG repeat were studied in family M-ADCA1. In all cases, the mother was affected. We detected a contraction in the number of CAG repeats (from 51 to 50 ) in an 
Table 3. Age at onset of early signs and symptoms and CAG-repeat number in presymptomatic analysis of SCA1 in family M-ADCA1

\begin{tabular}{|c|c|c|}
\hline Repeats & Age/Sex & Signs and symptoms \\
\hline 41 & $18 / \mathrm{F}$ & Asymptomatic \\
\hline 41 & $25 / \mathrm{M}$ & Asymptomatic \\
\hline 47 & $39 / \mathrm{F}$ & $\begin{array}{l}\text { Unsustained gaze-evoked upward- } \\
\text { beating nystagmus }\end{array}$ \\
\hline 47 & $39 / \mathrm{M}$ & Right upper limb tremor \\
\hline 49 & $28 / \mathrm{F}$ & Occasional unsteadiness \\
\hline 50 & $27 / \mathrm{M}$ & $\begin{array}{l}\text { Unsteadiness when rising from a } \\
\text { chair }\end{array}$ \\
\hline 52 & $18 / \mathrm{M}$ & $\begin{array}{l}\text { Unsustained gaze-evoked upward- } \\
\text { beating nystagmus }\end{array}$ \\
\hline 53 & $25 / \mathrm{F}$ & Slight tremor in hands \\
\hline 59 & $18 / \mathrm{F}$ & Occasional unsteadiness \\
\hline
\end{tabular}

otherwise healthy 27-year-old individual who reported occasional unsteadiness, whereas his mother, with 51 repeats, had had a well-defined ataxia at the same age. Stabilization of the repeat number (41 repeats) was observed in two subjects, while in the other three patients, the repeat expanded by three copies (from 50 to 53 and from 49 to 52) and by two triplets (from 51 to 53).

Early manifestations in at-risk/mutated subjects. Nine of 33 at-risk individuals were diagnosed for SCA1 by genetic studies (at-risk/mutated). These patients did not fulfil the clinical criteria of SCA1. In some patients, minor symptoms of SCA1 were reported, such as occasional unsteadiness or instability after rising from a chair, or light signs were discovered by neurologic examination, such as brief unsustained gaze-evoked upward-beating nystagmus, right upper limb tremor, light bilateral tremor in hands, hyperreflexia, slight ataxia, and lingual tremor or dysarthria (table 3 ). None of these nine patients considered themselves affected by SCA1. Only two of the at-risk/mutated individuals were found to be completely normal on examination, and they did not report abnormalities in the questionnaire. None of the 24 subjects categorized as at-risk/normal had abnormalities in the questionnaire or on neurologic examination.

Discussion. Family M-ADCA1 is one of the largest and most homogeneous SCA1 kindreds linked to chromosome $6 \mathrm{p}$ that has been described. Chronologic data of age of onset, mean duration of disease, and mean age at death in family M-ADCA1 are similar to those of other SCA1 families. ${ }^{4,7-9,20,21}$

We found high frequency of dysphagia, with the early appearance of choking. Cachexia not related to dysphagia during the midcourse of the disease was present in half the patients. The progressive restrictive respiratory failure detected in SCA1 patients may be a consequence of an associated motoneuron disease but has not previously been recognized as an important sign of SCA1; this feature complicates the course of the disease.

Neurologic examination of at-risk patients revealed subtle signs. A slight tremor, unsustained gaze-evoked upward-beating nystagmus, or a sensation of instability when rising from a chair or when going down stairs are characteristic hallmarks of SCA. We established that (1) minor signs and symptoms begin early in the course of disease, before full clinical diagnosis; (2) these manifestations are intermittent in some patients before the inexorable course begins; (3) emotional factors can occasionally cause a symptom or a sign to appear, and it subsides days or weeks later; and (4) in an at-risk subject, these mild symptoms and signs can herald the full development of SCA1 by years.

The disease in family M-ADCA1 was tightly linked to marker D6S89 at 6p, and an analysis of the CAG repeat showed an expansion above normal values in 10 clinically affected individuals, seven individuals with early minor signs and symptoms, and two asymptomatic individuals. ${ }^{15}$ There is a correlation between the number of repeats and the age of onset of SCA1, with a higher number of repeats correlating with an earlier age of onset. ${ }^{14,15}$ Juvenile onset of SCA1 has been found to be associated with 60 or more repeats. ${ }^{14}$ We have shown that the largest number of repeats in the M-ADCA1 kindred was 59 in a clinically unaffected 18-year-old at-risk female. Anticipation and juvenile onset were present in other SCA1 kindreds ${ }^{7,14,21}$ with numbers of $(\mathrm{CAG})_{\mathrm{n}}$ repeats between 69 and 81 . We have not detected young or juvenile-onset patients, concordant with the smaller mean number of $(\mathrm{CAG})_{n}$ repeats (average, 48) in our family.

The size of the CAG repeat increased from the eighth generation to the ninth generation in family M-ADCA1, as found in other SCA1 kindreds, ${ }^{14}$ providing a basis for the molecular mechanism involved in anticipation for SCA1. In Huntington's disease (HD), ${ }^{22}$ myotonic dystrophy (DM), ${ }^{23,24}$ and in two large SCA1 families, ${ }^{14}$ there is a preponderance of male transmission in juvenile patients detected. In family M-ADCA1, we have detected a shorter course of the disease and an earlier age at death in the offspring of affected fathers compared with the offspring of affected mothers ${ }^{15}$; this was not usually found in other SCA1 families, ${ }^{4,7-9,20,21}$ but the difference between the number of repeats in both groups was not significant. An early onset of SCA symptoms has previously been associated with a shorter and worse course of the disease. ${ }^{25}$ This was not the rule in family M-ADCA1, in which we did not find a statistical correlation between the age of onset and the duration of the disease (data not shown). For the same number of repeats, disease onset is earlier in men than in women. Another feature in family M-ADCA1 was a continuous male transmission ending in five offspring of an affected male without any of them being affected. Moreover, an only-female transmission ended in only one sib of six affected.

In some cases, absence of CAG expansion was 
present with maternal transmission of the disease, as previously observed in $\mathrm{DM}^{24,26}$ and in $\mathrm{HD} .{ }^{22}$ Contraction (a decrease of the size of the CAG repeat) may be present in $\mathrm{DM},{ }^{23,24,26}$ in $\mathrm{HD},{ }^{22}$ and in fragile $\mathrm{X}$ syndrome. ${ }^{27}$ These peculiar situations suggest that other mechanisms exist to restrict the transmission of the SCA1 mutation.

SCA1 is a trinucleotide repeat disease like $\mathrm{DM},{ }^{24}$ $\mathrm{HD},{ }^{22}$ fragile X syndrome, ${ }^{27}$ and Kennedy's disease. ${ }^{28}$ In most of the descendants, the repeat expands, but in others it stabilizes or contracts, and these mechanisms seem to act simultaneously in different branches of a kindred. In some branches, the disease seems to increase in frequency, whereas in others it decreases and even disappears. The recent discovery of the CAG-repeat expansion has improved presymptomatic diagnosis of SCA1 and is an important tool for studying the characteristics of the genetic transmission of this disease. ${ }^{14,15}$

The classification of autosomal dominant SCAs may change rapidly. Besides the first type of dominant ataxia linked to chromosome 6 (SCA1), 3,4,6-8,11-15,20,21 recent advances suggest the existence of more than four different genetic types of dominant ataxia. A second locus (SCA2) has been linked to chromosome 12 in Cuban and other pedigrees. ${ }^{12,29,30}$ The locus responsible for Machado-Joseph disease (MJD), with a suggested name of SCA3, another neurodegenerative process related to SCA, maps to chromosome $14 .^{31}$ Finally, genetic studies have excluded linkage to chromosomes 6 and 12 in several French families with a different phenotype of MJD, suggesting a fourth locus (SCA4). ${ }^{32}$ Nevertheless, although the total number of different SCA loci remains unknown, autosomal dominant ataxia heterogeneity is beginning to be classified at the molecular level. Knowledge about the SCA1 gene and the mutation mechanism of this disease should improve our understanding of other dominant ataxias.

\section{Acknowledgments}

We thank E. Bartoli for technical assistance and Dr. Melanie Pritchard for useful comments and help with the manuscript. We also thank Dr. J. Berciano for his helpful discussions on hereditary ataxias. We are indebted to J.R., E.R., and I.G. and to all the members of the M-ADCA1 family for their cooperation and support during this work. We are grateful to the Neurology Departments of Hospital de Sant Pau and Hospital de la Vall d'Hebrón. The Institut Català de la Salut (Generalitat of Catalonia) gave financial support for this work.

\section{References}

1. Harding AE. Classification of the hereditary ataxias and paraplegias. Lancet 1983;1:1151-1155.

2. Berciano J. Olivopontocerebellar atrophy: a review of 117 cases. J Neurol Sci 1982;53:253-272.

3. Yakura H, Wakisaka A, Fujimoto S, Itakura K. Hereditary ataxia and HLA genotypes. N Engl J Med 1974;291:154-155.

4. Jackson JF, Currier RD, Terasaki PI, Morton NE. Spinocerebellar ataxia and HLA linkage: risk prediction by HLA typing. N Engl J Med 1977;296:1138-1141.
5. Morton NE, Lalouel JM, Jackson JF, Currier RD, Yee S. Linkage studies in spinocerebellar ataxia (SCA). Am J Med Genet 1980;6:251-257

6. Ranum LPW, Duvick LA, Rich SS, Schut LJ, Litt M, Orr HT. Localization of the autosomal dominant HLA-linked spinocerebellar ataxia (SCA1) locus, in two kindreds, within an 8 -cM subregion of chromosome $6 \mathrm{p}$. Am J Hum Genet 1991;49:31-41.

7. Zoghbi HY, Pollack MS, Lyons LA, Ferrell RE, Daiger SP, Beaudet AL. Spinocerebellar ataxia: variable age of onset and linkage to human leukocyte antigen in a large kindred. Ann Neurol 1988;23:580-584

8. Spadaro M, Giunti P, Lulli P, et al, HLA-linked spinocerebellar ataxia: a clinical and genetic study of large Italian kindreds. Acta Neurol Scand 1992;85:257-265.

9. Sasaki H, Wakisaka A, Koyama T, et al. Spinocerebellar ataxia 1: clinical study of 17 patients in a large pedigree. No To Shinkei 1993;45:502-508

10. Genis D, Dávalos A, Molins A, Rosell J, Volpini V. Estudio clínico de una extensa estirpe (familia $M$ ) afecta de ataxia cerebelosa dominante. In: Berciano J, ed. Ataxias y paraplejias hereditarias: aspectos clínicos y genéticos. Madrid: Ediciones Ergon S.A., 1993:175-187.

11. Keats BJB, Pollack MS, McCall A, et al. Tight linkage of the gene for spinocerebellar ataxia to D6S89 on the short arm of chromosome 6 in a kindred for which close linkage to both HLA and F13A1 is excluded. Am J Hum Genet 1991;49:972977.

12. Zoghbi HY, Jodice C, Sandkuijl LA, et al. The gene for autosomal dominant spinocerebellar ataxia (SCA1) maps telomeric to the HLA complex and is closely linked to the D6S89 locus in three large kindreds. Am J Hum Genet 1991;49:2330 .

13. Sasaki H, Wakisaka A, Tashiro K, Hamada T, Shima K. Linkage study of hereditary olivopontocerebellar atrophy: genetic evidence for locus heterogeneity in Japanese cases. Rinsho Shinkeigaku 1992;32:17-22.

14. Orr HT, Ming-yi C, Banfi S, et al. Expansion of an unstable trinucleotide CAG repeat in spinocerebellar ataxia type 1. Nat Genet 1993;4:221-226.

15. Matilla T, Volpini V, Genis D, et al. Presymptomatic analysis of spinocerebellar ataxia type 1 (SCA1) via the expansion of the SCA1 CAG-repeat in a large pedigree displaying anticipation and parental male bias. Hum Mol Genet 1993;2:2123-2128.

16. Ferrer I, Genis D, Dávalos A, Bernadó L, Sant F, Serrano T. The Purkinje cell in olivopontocerebellar atrophy: a Golgi and immunocytochemical study. Neuropathol Appl Neurobiol 1994;20:38-46.

17. Fuentes JJ, Banchs I, Volpini V, Estivill X. Genetic variation of microsatellite markers D1S117, D6S89, D11S35, APOC2, and D21S168 in the Spanish population. Int J Legal Med 1993;105:271-277.

18. Ranum LPW, Chung MY, Duvick LA, Zoghbi HY, Orr HT. Dinucleotide repeat polymorphism at the D6S109 locus [letter]. Nucleic Acids Res 1991;19:1171.

19. Ott J. Analysis of human genetic linkage. 2nd ed. Baltimore: Johns Hopkins University Press, 1991.

20. Nino HE, Noreen HJ, Dubey DP, et al. A family with hereditary ataxia: HLA typing. Neurology 1980;30:12-20.

21. Haines JL, Schut LJ, Weitkamp LR, Thayer M, Anderson VE. Spinocerebellar ataxia in a large kindred: age at onset, reproduction, and genetic linkage studies. Neurology $1984 ; 34: 1542-1548$.

22. The Huntington's Disease Collaborative Research Group. A novel gene containing a trinucleotide repeat that is expanded and unstable on Huntington's disease chromosomes. Cell 1993;72:971-983.

23. Ashizawa T, Dunne CJ, Dubel JR, et al. Anticipation in myotonic dystrophy. I. Statistical verification based on clinical and haplotype findings. Neurology 1992;42:1871-1877.

24. Ashizawa T, Dubel JR, Dunne PW, et al. Anticipation in myotonic dystrophy. II. Complex relationships between clinical findings and structure of the GCT repeat. Neurology 1992;42:1877-1883.

25. Currier RD, Jackson JF, Meydrech EF. Progression rate and 
age at onset are related in autosomal dominant neurologic diseases. Neurology 1982;32:907-909.

26. Hunter AGW, Jacob P, O'Hoy K, et al. Decrease in the size of the myotonic dystrophy CTG repeat during transmission from parent to child: implications for genetic counselling and genetic anticipation. Am J Med Genet 1993;45:401-407.

27. Yu S, Mulley J, Loesch D, et al. Fragile X syndrome: unique genetics of the heritable unstable element. Am J Hum Genet 1992;50:968-980.

28. La Spada AR, Wilson EM, Lubahn DB, Harding AE, Fischbeck $\mathrm{KH}$. Androgen receptor gene mutations in X-linked spinal and bulbar muscular atrophy. Nature 1991;352:77-79.

29. Gispert S, Twells R, Orozco G, et al. Chromosomal assignment of the second locus for autosomal dominant cerebellar ataxia (SCA2) to chromosome 12q23-24. 1. Nat Genet 1993; 4:295-299.

30. Lopes-Cendes I, Andermann E, Gerstenbrand F, et al. Linkage studies in spinocerebellar ataxia (SCA): evidence showing that the recently described SCA2 locus is not a private gene [abstract]. Neurology 1993;43(suppl 2):A359.

31. Takiyama Y, Nishizawa M, Tanaka H, et al. The gene for Machado-Joseph disease maps to human chromosome 14q. Nat Genet 1993;4:300-304.

32. Khati G, Stevanin G, Durr A, et al. Genetic heterogeneity of autosomal dominant cerebellar ataxia type 1: clinical and genetic analysis of 10 French families. Neurology 1993;43: $1131-1137$

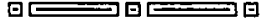

\section{Assessment of MRI criteria for MS in Japanese MS and HAM/TSP}

\author{
Y. Kuroda, MD; M. Matsui, MD; M. Yukitake, MD; K. Kurohara, MD; H. Takashima, MD; \\ Y. Takashima, MD; C. Endo, MD; A. Kato, MD; and F. Mihara, MD
}

Article abstract-We evaluated the usefulness of the MRI criteria for multiple sclerosis (MS) proposed by Paty et al and Fazekas et al in 36 Japanese MS patients, using HTLV-I-associated myelopathy (HAM)/tropical spastic paraparesis (TSP) as the control. Although 30 of $36 \mathrm{HAM} / \mathrm{TSP}$ patients had multiple white matter lesions on $\mathrm{T}_{2}$-weighted cranial MRI, only two fulfilled the MRI criteria for MS. At the same time, 31 of the 36 MS patients fulfilled the primary MRI criterion, yielding $93 \%$ specificity and $86 \%$ sensitivity for the criterion. MS has disease-specific MRI abnormalities.

NEUROLOGY 1995;45:30-33

Human T-cell lymphotropic virus type I (HTLV-I)associated myelopathy (HAM)/tropical spastic paraparesis (TSP) is a chronic inflammatory disease primarily affecting the spinal cord. ${ }^{1-3}$ Although the pathogenesis remains unclear, much evidence suggests that HAM/TSP is similar to multiple sclerosis (MS); the presence of pleocytosis, increased IgG and oligoclonal IgG in the CSF, ${ }^{1-3}$ predominant occurrence in adult women, ${ }^{1-3}$ and efficacy of corticosteroids and interferon- $\alpha$ or $-\beta^{1,4-6}$ are reported in both conditions. The neuropathologic findings consist of demyelination and T-cell infiltrates, ${ }^{3,7,8}$ and $\mathrm{T}_{2}$-weighted MRI detects multifocal lesions in the cerebral white matter in both conditions..$^{9,10} \mathrm{Re}$ cently, Paty et $\mathrm{al}^{11,12}$ and Fazekas et $\mathrm{al}^{13,14}$ proposed MRI criteria for MS. Although they verified the usefulness of the criteria in controlled studies, none of the studies included HAM/TSP as the control. ${ }^{11,13,14}$ We assessed the specificity of the MRI criteria for MS in Japanese MS and HAM/TSP patients.
Methods. Brain MRI findings in 36 patients with clinically definite or probable MS and 36 patients with clinically definite HAM/TSP were reviewed. The diagnosis of MS was made according to the criteria of Schumacher et $\mathrm{al},{ }^{15}$ and that of HAM/TSP according to the criteria of Osame et al. ${ }^{16}$ The MS group consisted of 29 women and seven men, and the HAM/TSP group comprised 22 women and 14 men. The mean age at MRI was 44 years (range, 13 to 70 years) for the MS group and 54 years (range, 28 to 72 years) for the HAM/TSP group. Although we included five HAM/TSP patients with hypertension and one HAM/TSP patient with CREST syndrome and Sjögren's syndrome, no patient in either group had a history of cerebral stroke.

All MRI studies were performed at a high field strength (1.5 tesla) on a superconducting General Electric Signa MR imaging system. $\mathrm{T}_{2}$-weighted spin-echo (SE) images were obtained using a repetition time of $2,000 \mathrm{msec}$, an echo time of $80 \mathrm{msec}$, and 1 excitation (SE $2,000 / 80 / 1$ ) in the axial plane. Intermediate weighted (SE $2,000 / 20$ or 30 ) images were obtained simultaneously. $\mathrm{T}_{1-}$ weighted SE images (SE 400/20/2 or $600 / 25 / 2$ ) were also obtained in all patients. The multislice technique was

From the Departments of Internal Medicine (Division of Neurology) (Drs. Kuroda, Matsui, Yukitake, Kurohara, H. Takashima, Y. Takashima, and Endo) and Radiology (Drs. Kato and Mihara), Saga Medical School, Saga, Japan.

Received May 25, 1994. Accepted in final form July 21, 1994.

Address correspondence and reprint requests to Dr. Yasuo Kuroda, Department of Internal Medicine, Saga Medical School, Saga 849, Japan. 